\title{
PROFILE OF FIRST 100 IN-PATIENTS IN DE-ADDICTION WARD T.U. TEACHING HOSPITAL, NEPAL
}

\author{
Ojha S P*, Pokharel A*, Koirala N R*, Sharma V D*, \\ Pradhan S N, Nepal M K*, Timsina C L*
}

\section{ABSTRACT}

Men and women suffering from the problems of various psychoactive substance abuse were helped to come out of the problem by the Department of Psychiatry and Mental Health since it's establishment in 1986. Since the De-addiction ward started functioning under the Department of Psychiatry and Mental Health, T.U. Teaching Hospital (TUTH) from February, 2000 A.D., people suffering from various drugs related problems have received in-patient care. This study describes the profile of first 100 psychoactive substance abusers admitted in this ward. The first hundred patients were admitted in a period of 5 months and 2 weeks, in an average of 18 patients per month. Eighty eight males, the average age being $33.3+10.98$ years. Seventy were married. The average years of education was $8.56+4.94$ years. Alcohol $(n=58)$ was the commonest initial substance, followed by cannabis $(n=19)$ and cigarette $(n=11)$. Currently 60 were predominantly alcohol users and 36 predominantly opiate users. The majority were multiple substance users: 79 used alcohol, 37 used opiates, 25 used cannabis and 18 used benzodiazepines. Age at first use was 19.57+5.54 years and duration of continuous use was $\mathbf{5 . 8 8 + 4 . 4 7}$ years. Eleven ( 8 males) were HIV ELISA reactive, all of whom were parenteral opiate abusers. Thirty-nine ( 35 males) had fatty changes in liver and 6 (all males) had cirrhotic changes in liver. Those 45 persons with liver abnormality were all alcohol users.

\section{Key Words: psychoactive substance, alcohol, opiates, HIV, liver changes.}

\section{INTRODUCTION}

Men and women suffering from the problems of various psychoactive substance abuse are receiving necessary mental health care from the Department of Psychiatry and Mental Health since its establishment in 1986. A study over one year showed that 63 patients suffering from substance use disorders received out patient management, which made up $4.39 \%$ of the total outpatients over that duration. ${ }^{1}$ In the study on emergency psychiatric consultations, this group of patients made $15.66 \%$, larger than those suffering from schizophrenia and other related psychotic disorders. ${ }^{2}$
Many needed in-patient service, which was being provided by admitting them in the Psychiatry ward of TUTH. The need of a separate in-patient set up for such people was felt for long, which became a reality after the establishment of the Deaddiction ward under the Department of Psychiatry and Mental Health, TUTH. Since the ward started operating from February 2000, people suffering from various drugs related problems have received in-patient care as well as various activities for relapse prevention as outpatients. This 10 bedded ward has however not always been able to serve all those who needed in-patient care and at times such patients had to be admitted

* Dept. of Psychiatry and Mental Health, Institute of Medicine, Tribhuvan University, Kathmandu, Nepal.

Address for correspondence : Dr. Saroj Prasad Ojha

Dept. of Psychiatry

TU Teaching Hospital, Kathmandu, Nepal.

Email: sojha@healthnet.org.np 
in the Psychiatric Ward along with patients suffering from various other psychiatric disorders. ${ }^{3}$ In the present study we intend to analyze the profile of first 100 in-patients.

\section{MATERIAL AND METHOD}

This is a retrospective and descriptive study of the first one hundred patients admitted in the De-addiction Ward of TUTH. Case records were obtained from the medical record section of the hospital. A self-designed proforma was used to record the socio-demographic data and other relevant information about psychoactive substance use and their various complications. The information was kept confidential. Data analysis was done in SPSS version 7.5. ${ }^{4}$

\section{RESULTS}

Table I : Socio-demographic Profile

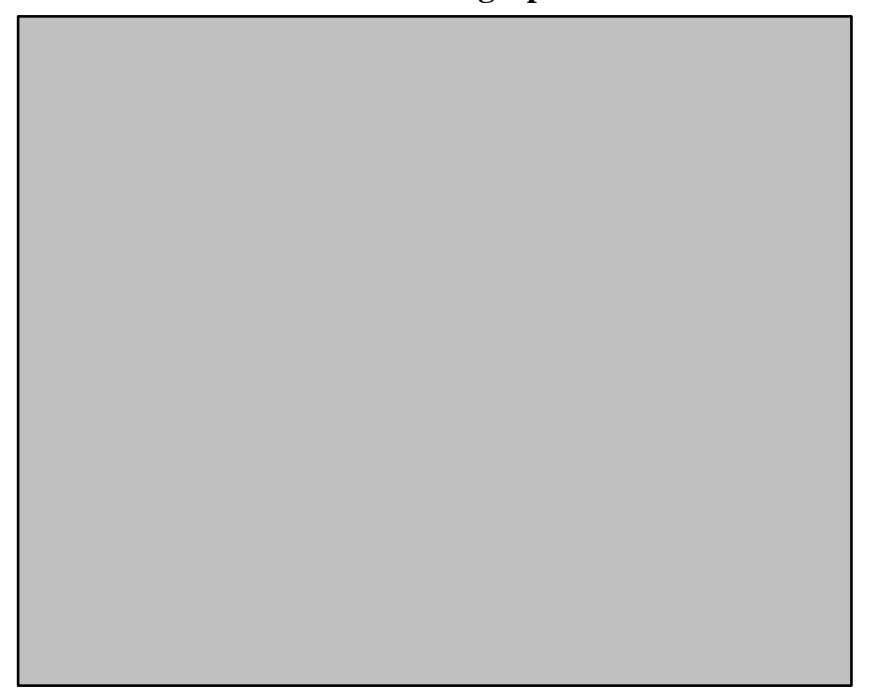

Table I shows that 88 were males. The majority was in the age group $21-30$ years. The average age was $33.3+10.98$ years. Seventy were married. More than half had received their education under high school level, the average being $8.56+4.94$ years of education.

Table II : Substance used initially

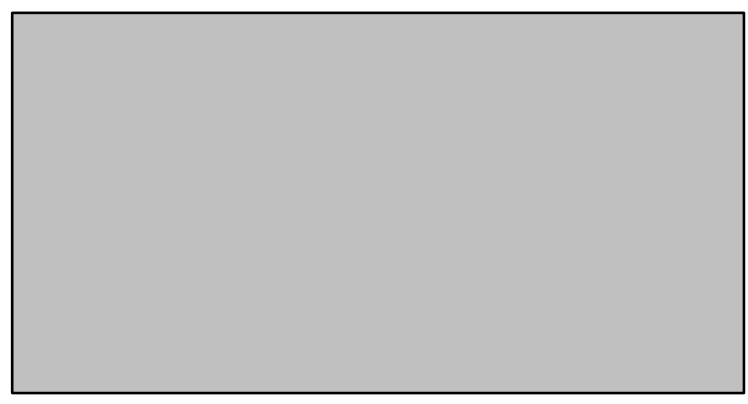

Table II shows 58 had began by abusing alcohol, 19 cannabis and 11 cigarette. Only 10 had started by abusing opioids (codeine [5], heroin [4] and buprenorphin [1]).
Out of 60 alcohol users, 54 used it as single substance and 6 as the major substance among multiple substances. This number was 36 for opiates, 2 as single users and 34 as the major substance among multiple substances. There were 3 persons who were regarded as cannabis abusers. The total number of alcohol consumers were 79 when we consider alcohol use in those who were using multiple substances. This number for cannabis rises to 25 and for opiates, only modestly to 37 . Among those with Multiple substances users with alcohol as predominant substance $(n=6)$, all were consuming cannabis and none were using opiates. Among those with multiple substances users with opiates as predominant substance $(n=34), 15$ were consuming cannabis and 19 were also using opiates. A multiple substances users with benzodiazepine as predominant substance was also consuming cannabis and opiate.

Table III : Current Substance

Table III shows that $60 \%$ were predominantly alcohol users and $36 \%$ predominantly opiate users. Sixty five patients were using the substances continuously for 2 to 10 years. Only 23 were continuous users for 2 years or less. Forty had age at first use $16-20$ years, while 25 started the substances when they were between $21-25$ years of their life. Twenty-two persons had started before they turned 16 .

Table IV : Age at first use, education and duration of continuous use

Table IV shows duration of continuous use was $5.88+4.47$ years. This figure was highest for people more than 50 years. Same table also shows that the mean age at first use was $19.57+5.54$ years. This figure raised as age of the patients increased. This table also illustrates duration of continuous use and age at first use in relation to level of education. There was an inverse relationship between level of education and duration of continuous use; and as the level of education increased, age at first use was also found to be increased. 
Table V : HIV infection and liver state

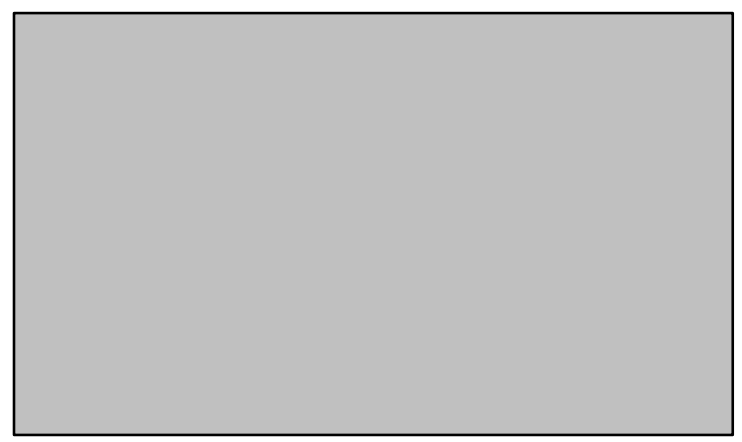

Table $\mathrm{V}$ shows that 11 ( 8 males) were HIV ELISA reactive. It was not tested in 61 cases (unsuspected $=60$, consent not available=1). Same table also shows that 39 (35 males) had fatty changes in liver and 6 (all males) had cirrhotic changes in liver. These 45 persons with liver abnormality were all alcohol users (Table VI).

Table VI : Liver state according to alcohol use

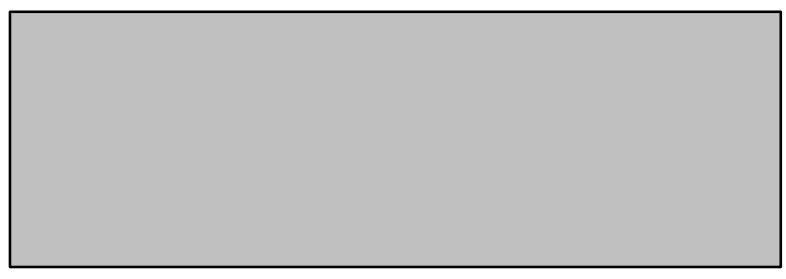

Table VII : HIV status according to mode of substance abuse

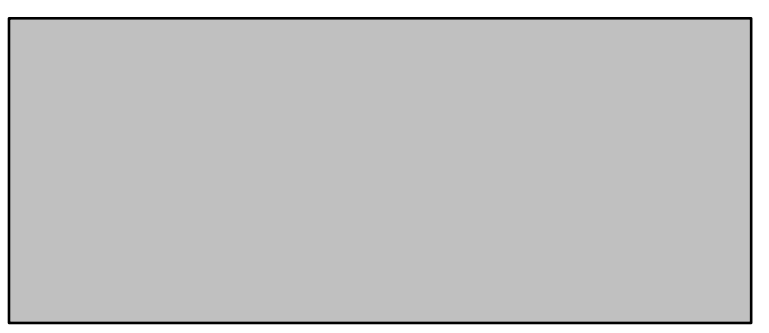

Table VII shows that those who were HIV ELISA reactive, all were parenteral opiate abusers. Out of 30 cases using the psychoactive substances through parenteral route, 29 got the test done. $11(38 \%)$ of those who used parenteral route for drug administration were found to be HIV ELISA reactive.

\section{DISCUSSION}

ICD $-10^{5}$ and DSM - IV both have included psychoactive substance abuse under mental and behavioural disorders. Psychoactive substance abuse is closely related with other psychiatric disorders and physical diseases and complications. Apart from the type of the substance, the mode of administration also brings about complications many a times not a direct effect of the substances. Study of substance abuse had high importance.
The first hundred patients receiving treatment over a duration of five and half months is a good beginning. Regarding comparable socio-demographic profiles, these patients were similar in mean age and marital status to out-patients, ${ }^{1}$ emergency psychiatric population ${ }^{2}$ and in-patients. ${ }^{3}$ Male preponderance in the present study population can suggest different issues. Although a community survey of psychoactive substance abuse in our country is not known, we can presume it the effect of really far larger male preponderance among included psychoactive substance abuses in the community. We, however, may also claim that it's due to stigma females do not seek treatment in public hospital for this kind of problem particularly.

For the majority the initial substance of abuse was alcohol. The second most common substance was cannabis. Although almost 4 out of every 10 patients were opiate abusers, for only 1 out of 10 it was the initial substance. Targeting alcohol and cannabis should be considered in awareness raising programmes.

Liver diseases are among many physical complications of long term alcohol abusers. Cirrhosis is one of the fatal complications. Gelder et $\mathrm{al}^{7}$ mentions that $10-20 \%$ of the alcohol dependent develop cirrhosis. Six (10\%) out of 60 predominant alcohol abusers developing cirrhosis in our study accords with this finding. Life expectancy also has been noted to be reduced in this group of patients. Follow-up investigations have studied mainly middle-aged men alcohol dependents, in whom overall mortality is at least twice the expected rate. ${ }^{8,9}$

The relationship between HIV infection and parenteral drug abuse has been known for long. Intravenous drug abuse associated with use of already used syringes / needles has been found to be responsible for rapid spread of HIV and other infectious disease in this group of people. ${ }^{10}$ The possible explosion of HIV in our community has forced us to think about the possible methods of timely intervention. Eleven patients, who tested positive for HIV in the study population, were all parenteral drug abusers. Harm reduction programme has been advocated in the recent time by many. ${ }^{11}$ Although harm reduction programmes do exist in Nepal, these should be more extensive to control the explosive increase in HIV infections.

Although drug withdrawal (or detoxification) by itself has no long term outcome, ${ }^{12}$ this process is initial part of a wider programme. With appropriate combination of detoxification and relapse prevention programmes, this newly established setting should be able to help in controlling the problem of psychoactive substance abuse, which is slowly engulfing our citizens in their productive age. 
REFERENCES

1. Regmi SK, Khalid A, Nepal MK, Pokharel A. A study of sociodemographic charisteristics anddiagnostic profile in psychiatric outpatients. Nepalese J ournal of Psychiatry. 1999; 1: 26-33.

2. Khalid A, Regmi SK, Koirala NR, Nepal MK, Pokharel A. Psychiatric Emergencies ina General Hospital Setting.J oumal of Institute of Medicine. 1999; 21: 207-214.

3. Pokharel A, PradhanSN, Chaparain GC, AdhikariS, Ohja SP, Sharma VD, Koirala NR. Sociodemographic chanisteristics and diagnostic profile of patients admitted in Psychiatry ward of Tribhuvan University Teaching Hospital. NepaleseJ oumal of Psychiatry. 2001; 2(1): 26-33.

4. Norusis MJ . SPSS for windows, base system user's guide, release 7.5. Chicage:SPSS Inc., 1997.

5. W.H.O. Intemational Classification of Disease and Related Health Problems. Tenth Revision. Clinical Description and Diagnostic Guidelines. Geneva: World Health Organization, 1992.
6. American Psychiatric Association. Diagnostic and Statistical Manual of Mental Disorders, Fourth Edition. Washington, DC, 1994

7. Gelder M, Gath D, Mayou R, Cowen P. Oxford Textbook of Psychiatry. $3^{\text {rd }}$ ed. Somerset Oxford University Press, 1996.

8. Shaper AG. Alcohol and mortality: a review of prospective studies. BritishJ ournal of Addiction. 1990; 85: 837-847.

9. Marshall EJ , Edwards G, Taylor C Mortality in men with drinking problems: a 20-year follow-up. Addiction. 1994; 89: 12931298.

10. Desai NG, Gupta DK, Khurshid KA. Substances Use Disorders. Textbook of Postgraduate Psychiatry. 1997: 76-89.

11. Cremers L, MatotJ P. Dimensions of drug and alcohol use and misuse in HIV risk behaviour. CurrentOpinion in Psychiatry. 1994; 7: 285-290.

12. Vaillant GE. Whatcan long-term follow-up teach us about relapseand prevention inaddiction? BritishJ oumal of Addiction. 1988; 83: 1147-1157. 